\title{
GERENCIANDO RELACIONAMENTOS COLABORATIVOS COM FORNECEDORES
}

\section{RESUMO}

O objetivo deste artigo é discutir a importância da confiança e o efeito dos investimentos em ativos específicos em relacionamentos colaborativos com fornecedores. 0 artigo ainda discute o efeito moderador da rede de informações sobre as ações colaborativas. Tomaram-se como base teórica as abordagens da economia de custos de transação e os estudos sobre canais de comercialização e redes organizacionais. Para testar as hipóteses formuladas, foram coletadas informações de atacadistas e outros distribuidores do setor de flores e vasos de plantas da Holanda. Os resultados sugerem que as informações obtidas na rede incentivam as ações conjuntas, como proteção para investimentos realizados pelos compradores. Constata-se também que o grau de confiança, os investimentos específicos e as informações obtidas na rede facilitam a coordenação de relacionamentos entre fornecedores e compradores.

\section{Danny Pimentel Claro \\ IBMEC-SP e USP}

\section{Priscila Borin de Oliveira Claro}

Universidade Federal de Lavras

ABSTRACT The aim of this paper is to discuss the importance of trust and the effect of specific assets investments over collaborative relationships with suppliers, and also to discuss the moderating effect of the information network on such joint actions. As theoretical foundations, we use transaction cost economics, network perspectives and marketing. In order to verify our four hypothesis, we collected information from the wholesalers and other merchant-distributors in the Dutch flower industry. The results suggest that buyers temper their specific investments to the degree of joint action according to the information that is obtained in the network. The degrees of trust, specific investments and the information from the network facilitate the coordination of a buyer-supplier relationship.

PALAVRAS-CHAVE Relacionamento cliente-fornecedor, gerenciamento da cadeia de suprimentos, confiança, redes de negócios. KEY WORDS Buyer-supplier relationship, supply chain management, trust, business networks. 


\section{INTRODUÇÃO}

Durante os últimos anos, os relacionamentos entre fornecedores e compradores sofreram mudanças significativas. Especialistas como Ford et al. (2003) afirmam que os relacionamentos baseados em ações colaborativas, parcerias e al ianças estratégicas estão se tornando cada vez mais comuns. A principal razão para esse fenômeno é que se atribui a esses relacionamentos a obtenção de vantagens competitivas. Stern et al. (1996) retratam o exemplo de atacadistas que mantêm relacionamentos colaborativos com fornecedores. Esses atacadistas podem garantir o recebimento de mercadorias em épocas de escassez de produtos, receber informações sobre novos produtos, produtos mais vendidos, atividades da concorrência, preços no mercado e níveis gerais de estoque.

Pesquisas anteriores enfatizaram a importância atribuída à confiança no desenvol vimento da colaboração (Anderson e Narus, 1990; Kim, 1999) e o papel da colaboração para salvaguardar os investimentos em ativos específicos, aqueles realizados pelo comprador para lidar com um determinado fornecedor (Heide e John, 1990). Além disso, as empresas estão utilizando cada vez mais suas redes organizacionais de relacionamentos como apoio para a efetivação da transação (Gulati et al., 2000; Omta et al., 2001).

Este artigo trata da relação das empresas com os fornecedores e analisa os el ementos motivadores da colaboração. 0 objetivo do trabalho é discutir a importância da confiança e o efeito dos ativos específicos nos relacionamentos colaborativos com fornecedores. Discute-se também o estímulo à colaboração do efeito moderador da informação obtida com outras organizações que formam uma rede de relacionamentos.

Foi realizada uma pesquisa empírica com base na perspectiva dos compradores, inclusive atacadistas, exportadores, centros de jardinagem e comércios do tipo "pague e leve". Esses compradores fazem parte do setor de flores holandês, famoso pelas transações de leilão reverso. Estas utilizam o princípio de redução de preços: o mostrador de um relógio indica o preço máximo, que diminui até o produto ser vendido ao primeiro comprador que responder à oferta. $\mathrm{N}$ as transações via leilão reverso, a padronização de produtos em combinação com el ementos de mercado - preço, oferta e demanda - é o fator básico que determina o mecanismo de coordenação. Em tal condição, não existem ações conjuntas (Zylbersztajn et al., 1992).
Entretanto, uma forte tendência tem mudado a natureza dos relacionamentos desse setor. Desde 1996, os compradores aumentaram substancial mente a quantidade de compras realizadas fora do leilão, por meio da utilização de linhas fixas. As linhas fixas conferem flexibilidade com relação aos locais e horários de entrega, bem como uma redução em termos de perdas de produtos e de impactos negativos devido a incertezas de mercado.

0 restante do artigo está organizado da seguinte forma: a segunda seção trata da base teórica e apresenta as hipóteses que serão testadas pelo estudo de campo; a terceira seção traz a metodologia de pesquisa; a quarta seção apresenta os resultados da pesquisa; a quinta seção traz uma discussão acerca das correlações encontradas; e a última seção apresenta as implicações para a prática gerencial, discute as limitações do trabal ho e traz propostas para futuras pesquisas.

\section{REFERENCIAL TEÓRICO}

\section{Colaboração por meio das ações conjuntas}

De acordo com Anderson e N arus (1990) e Morgan e Hunt (1994), colaboração se refere a situações nas quais os atores envolvidos em uma transação se esforçam para, juntos, alcançar suas metas. Dessa forma, há uma espécie de sobreposição dos limites organizacionais dos atores, uma vez que os fornecedores se envolvem em atividades que tradicionalmente são consideradas responsabilidades do comprador e vice-versa (Yilmaz e Hunt, 2001).

Segundo Heide e John (1992), a ação conjunta é o ponto de partida para a mudança de uma transação de mercado para uma transação relacional ou bilateral. Dessa forma, os atores se tornam parceiros, o que se manifesta por ações conjuntas de planejamento, de definição de metas e de controle de processos e resultados. As ações conjuntas também podem ser vistas como uma mistura de planejamento e resolução conjunta de problemas.

O planejamento conjunto, segundo Heide e John (1992), refere-se às atividades pelas quais as contingências futuras, deveres e responsabilidades de um relacionamento são explicitamente real izadas ex ante. Por exemplo, compradores e fornecedores envolvidos em atividades de planejamento conjunto podem compartilhar informações relevantes que podem influenciar seu volume futuro de negócios, como o investimento em novas unidades de produção. 0 planejamen- 
to conjunto funciona como um ponto de referência para os atores, eliminando a necessidade de especificações rígidas de deveres e obrigações, comumente encontrados em contratos (N eves, 2002).

Para Lusch e Brown (1996), a resolução conjunta de problemas se refere às atividades realizadas com 0 intuito de solucionar as discordâncias, falhas técnicas e outras situações inesperadas. Pode ser exemplificada por um comprador que, ao enfrentar problemas de qualidade do produto de um determinado fornecedor, procura saber a causa e, assim, tenta desenvolver a solução, em lugar de procurar por um novo fornecedor. Tal procedimento ajuda a consolidar o relacionamento. De acordo com Zaheer, McEvily e Perrone (1998), a resolução conjunta de problemas e o planejamento conjunto podem ser cruciais para o sucesso da empresa, dadas a complexidade e as ambigüidades dos relacionamentos com fornecedores.

As pesquisas que abordam o relacionamento entre clientes e fornecedores enfatizam as ações conjuntas, a confiança, os ativos específicos e a rede organizacional de relacionamento. Para Ganesan (1994), a confiança é um elemento importante por unir os atores e conferir ao relacionamento uma orientação de longo prazo.

A partir dessa base teórica, desenvolveu-se um modelo conceitual, representado pela Figura 1. Em seguida, apresentam-se quatro hipóteses, que serão testadas na pesquisa de campo.

\section{Antecedentes das ações conjuntas}

Para alguns autores (e.g. Doney et al., 1998; Galford e D rapeau, 2002), a confiança é considerada um elemento essencial da colaboração nos relacionamentos de negócios entre compradores e fornecedores. U ma base de confiança resulta em benefícios econômicos para os atores envolvidos.

De acordo com Wicks et al. (1999), a confiança existe devido a um laço emocional criado entre os indivíduos. Fornecedores e compradores envolvidos em um relacionamento de negócios considerado seguro - caracterizado pela confiança mútua - possuem conhecimento adequado, experiência e criatividade para identificar e resolver problemas, assim como para elaborar um planejamento efetivo. Para Anderson e Narus (1990), uma vez estabelecida uma base de confiança, as empresas aprendem que as ações conjuntas podem produzir melhores resultados do que ações isoladas, pautadas por interesses individuais.

Moorman et al. (1992) apresentaram e comprovaram a hipótese de que compradores que confiam nos parceiros estão mais engajados em ações conjuntas. Em convergência com o trabalho de Zand (1972), isso sugere que o comprador que confia em seu fornecedor troca informações pertinentes, compreensivas, precisas e oportunas, contribuindo para o planejamento e a resolução de problemas. Portanto, a confiança pode ser considerada como a base relacional para o desenvolvimento e a manutenção de ações conjuntas. Dessa forma, apresenta-se a primeira hipótese:

H1: Quanto maior a confiança de um comprador em seu fornecedor, mais o comprador se envolverá em ações conjuntas com o fornecedor.

Para Ford et al. (2003), a rede de um comprador é desenvolvida intencionalmente e inclui apenas um grupo selecionado de empresas. Compradores inseridos em tais redes estão mais propensos a confiar em seus fornecedores e, por isso, a se engajar em ações conjuntas. Devido aos altos níveis de informação compartilhada, parceiros em uma rede tendem a desenvolver e partilhar conhecimentos e experiências que correspondem às necessidades do comprador. Segundo Thorelli (1986), o envolvimento com fornecedores de reputação e competência reconheci das pelos membros da rede cria uma estrutura social e reduz a probabilidade de ações oportunistas. Eventualmente, alguns membros podem se colocar contra um determinado

Figura 1 - Modelo de pesquisa.



70 - oRAE - VOL. 44 - No4 
fornecedor de reputação duvidosa. Dessa forma, apresenta-se a segunda hipótese:

H2: A informação obtida pelo comprador com outras empresas na rede de rel acionamentos aumentará o efeito positivo da confiança nas ações conjuntas.

Os ativos específicos se referem a investimentos real izados pelo comprador para lidar com um determinado fornecedor. De acordo com Williamson (1985), esses ativos podem representar uma ameaça para o comprador, pois a especificidade reduz a reutilização e 0 valor do ativo em transações com outros fornecedores. Por exemplo, um comprador pode ter investido na promoção do produto de um fornecedor específico com a finalidade de abrir novos mercados. Porém, 0 fornecedor pode se apropriar do investimento feito pelo comprador por meio de vendas diretas ao novo mercado (Hobbs, 1996; Dyer e Singh, 1998). A preocupação fundamental dos compradores em relação aos ativos específicos é o desenvolvimento de salvaguardas satisfatórias que evitem comportamentos oportunistas.

As ações conjuntas constituem uma resposta efetiva aos investimentos em ativos específicos. A proteção dessas ações é assegurada por uma forma de controle do relacionamento. Para Heide (1994), as ações conjuntas viabilizam um sistema de governança bilateral, reduzindo a possibilidade de ações oportunistas virem a prejudicar o valor dos ativos específicos. Heide e John (1990) afirmam que as empresas que investem no relacionamento com os fornecedores tendem a se envolver em atividades que tradicionalmente são consideradas de domínio exclusivo do parceiro, para minimizar os riscos envolvidos. Adicionalmente, as ações conjuntas servem como uma coordenação mais efetiva das atividades e recursos que são parte de um relacionamento. Dessa forma, apresenta-se a terceira hipótese:

H3: Quanto maiores os investimentos em ativos específicos, maior quantidade de compradores se envolverão em ações conjuntas.

M embros da rede do comprador apresentarão restrições às ações destrutivas de um determinado fornecedor, especial mente se suas ações puderem comprometer os investimentos ou resultados econômicos de um membro da rede. Sem a existência da rede, tornase muito difícil para os compradores atualizar-se a respeito da integridade e do desempenho dos fornecedores.
Considerando que os compradores inseridos em uma rede podem reduzir os riscos de assimetria de informação, é provável que os benefícios potenciais da rede de informações para as ações conjuntas em resposta ao alto grau de investimentos em ativos específicos superem a preocupação do comprador quanto a fornecedores problemáticos. Dessa forma, apresenta-se a quarta hipótese:

H4: A informação obtida pelo comprador com outras empresas na rede de relacionamentos aumentará o efeito positivo dos investimentos em ativos específicos nas ações conjuntas.

É relevante ainda comentar o impacto de duas variáveis: tempo de relacionamento e porte da empresa. Anderson e Weitz (1989) e Bensaou e Venkatraman (1995) sugerem que os efeitos de um relacionamento de negócios entre fornecedores e compradores podem variar com a duração desse relacionamento e com 0 porte da empresa. A duração do relacionamento pode influenciar positivamente o comportamento colaborativo da empresa. Portanto, em relacionamentos mais antigos, nos quais os atores estão mais familiarizados uns com os outros, as ações conjuntas tendem a um maior êxito (Anderson e Weitz, 1989).

Em relação ao porte, é razoável supor que determinadas empresas se tornaram mai ores em virtude de suas realizações e conquistas e, portanto, experimentaram maior grau de colaboração com seus fornecedores. Os ganhos com a coordenação e a possibilidade de realizar ações de planejamento com os fornecedores maximizam a possibilidade de atingir os objetivos desejados.

\section{METODOLOGIA}

\section{Coleta dos dados}

Os dados foram coletados por meio de questionários, enviados aos informantes pelo correio. Com o intuito de minimizar informações distorcidas, buscou-se identificar informantes habituados a lidar diretamente com fornecedores. Os profissionais que preencheram os questionários foram os chefes dos departamentos de compras ou os colaboradores mais familiarizados com as compras de plantas e flores em vasos. As questões referiam-se ao fornecedor mais importante.

A partir de uma população de aproximadamente 1.000 compradores elegíveis, a amostra baseou-se numa lista de 350 compradores holandeses - ataca- 
distas, supermercados, exportadores e centros de jardinagem -, ativos em compras via linhas fixas. As empresas participantes receberam pelo correio um pacote com uma carta de introdução, um questionário e um envelope pago para o envio da resposta. Após um mês do envio, um segundo pacote foi enviado aos informantes que não haviam respondido ao primeiro questionário. Dessa forma, conseguiu-se um total de 81 questionários, dos quais 67 foram considerados válidos. A taxa de resposta foi considerada satisfatória (Claro, 2004), e não foram detectadas diferenças estatisticamente significativas entre os respondentes do primeiro e do segundo grupo.

Como instrumento de mensuração foi utilizada a escala Likert de sete pontos. A primeira versão do questionário foi baseada em itens utilizados em questionários de pesquisas anteriores. Para adaptá-los ao contexto da presente pesquisa, coletaram-se informações durante uma série de entrevistas com chefes dos departamentos de compras e com agentes de compras de quatro diferentes empresas compradoras e membros dos departamentos de mediação das cooperativas de fornecedores. Em seguida, os itens do questionário foram revisados por três pesquisadores da área e avaliados por especialistas do setor. Finalmente, realizouse um pré-teste com três diferentes compradores, no qual o chefe do departamento de compras respondeu ao questionário e identificou possíveis problemas e ambigüidades. Com isso, tentou-se assegurar a validade de conteúdo proveniente do instrumento de mensuração.

\section{Itens da pesquisa}

A investigação de campo envolveu seis variáveis:

- "Ação conjunta" foi avaliada por quatro subitens de planejamento, com coeficiente de confiabilidade alfa de Cronbach de 0,85 , e três subitens de resolução conjunta de problemas, com alfa de Cronbach de 0,89.

- "Planejamento conjunto" mediu quanto as contingências futuras e os conseqüentes deveres e responsabilidades de um relacionamento foram discutidos e explicitados (Heide e John, 1990).

- "Resolução conjunta de problemas" avaliou o grau de soluções conjuntas obtidas pelos compradores e fornecedores (Lusch e Brown, 1996).

- "Confiança" diz respeito à percepção de quanto o parceiro éhonesto esincero, enão agirá de formaa prejudicar o relacionamento em qualquer circunstância. Esse item foi avaliado por meio de cinco subitens, ea escala de mensuração foi baseada no estudo de Zaheer et al. (1998).

- "Investimento em ativos específicos" édefinido de acor- do com a percepção de um membro do relacionamento a respeito dos investimentos que foram realizados especificamente para uma tran sação com o fornecedor selecionado (Heide e John, 1992). Esses investimentos foram mensurados por dois subitens de investimentos físicos e três subitens de investimentos humanos, com alfa de Cronbach de 0,80.

- "Rede organizacional de relacionamentos" teve seu instrumento demensuração desenvolvido com base nas pesquisas de Anderson et al. (1994) e Blankenburg et al. (1999). Este item é capaz de captar o impacto dos cinco diferentes tipos de benefícios da informação fornecida por cinco diferentes conexões. As conexões se referem aos relacionamentos com empresas da mesma função no mercado (veja Figura 2). Os fornecedores do fornecedor (FF) são produtores de mudas e sementes, empresas que fornecem fertilizantes, produtos químicos, vasos, madeira e outros insumos. Outros compradores (OC) são empresas que se assemelham aos respondentes desta pesquisa. Outros fornecedores (OF) são empresas semelhantes ao fornecedor selecionado. Os consumidores dos compradores (CC) são supermercados, floriculturas, centros de jardinagem e pequenos atacadistas. Finalmente, agentes da cooperativa (AC) são membros do departamento de mediação das cooperativas, os quais possuem fortes contatos com fornecedores e compradores. Os benefícios da informação fornecida por cada conexão se referem ao apoio no estabelecimento de preços, fixação de quantidades, coordenação de processos produtivos, coordenação de operações de logística e previsão de ações futuras do comprador selecionado. Cada uma das cinco conexões é medida por esses cinco tipos de benefícios das informações, com alfa de Cronbach de 0,93.

As variáveis de controle do modelo foram "duração do relacionamento" e "porte da empresa":

- "Duração do relacionamento" se refere ao tempo em que o comprador está comprando produtos do fornecedor selecionado. Esse tempo foi medido em anos, por meio de uma questão aberta.

- "Porte da empresa" representa o faturamento total bruto do comprador no ano fiscal anterior. Essa variável foi medida por meio de uma questão fechada contendo oito intervalos de valor.

Os resultados da análise fatorial exploratória foram usados para depurar as escalas e testar a unidimensionalidade dos itens. Os fatores estimados são compostos de itens que refletem a mesma variável, sugerindo uni- 
dimensionalidade dos itens e validade convergente. As médias, os desvios padrão e a matriz de correlação para todos os itens são apresentados na Tabela 1. A associação das variáveis do modelo pode ser vista nos coeficientes de correlação que estão realçados. Embora várias correlações sejam significativas e positivas, todas elas estão abaixo de 0,80. De acordo com Hair et al. (1998), correlações abaixo de 0,80 são necessárias para evitar problemas de multicolinearidade.

A validade discriminante das variáveis foi testada com o uso do software LISREL 8.50 (Jöreskog e
Sörbom, 1996). Os model os não fixados apresentaram um ajuste superior significativo, sugerindo uma adequada validade discriminatória entre os pares de variáveis. Além disso, a confiabilidade do instrumento de coleta de dados utilizado excedeu o val or recomendado de 0,70 , refletindo sua boa qualidade.

\section{Especificação do modelo}

As hipóteses foram testadas com base na análise de regressão, empregando-se o software SPSS 10.0. Computando a média simples dos itens que refletem cada

Figura 2 - Rede estratégica.

Legenda

FF: fornecedor dos fornecedores

OF: outros fornecedores

AC: agentes da cooperativa

OC: outros compradores

FF: consumidores dos compradores

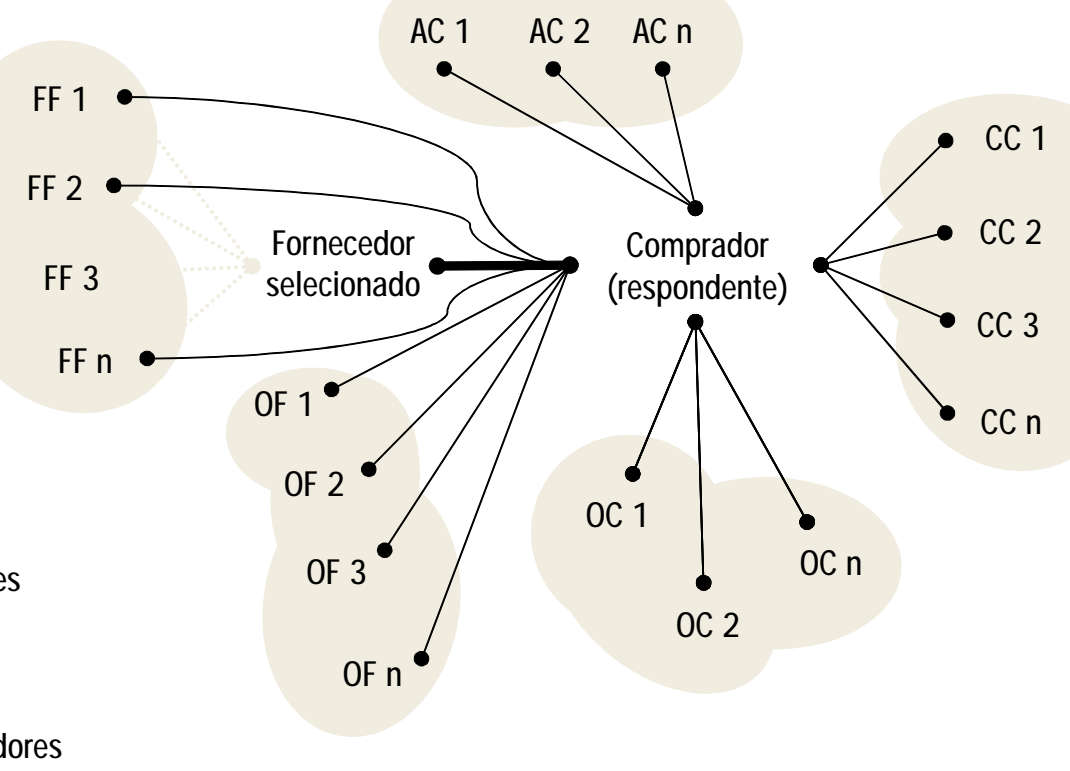

Tabela 1 - Correlações, desvios padrão e médias.

\begin{tabular}{|c|c|c|c|c|c|c|c|c|c|}
\hline & MÉDIA & $\begin{array}{l}\text { DESVIO } \\
\text { PADRÃO }\end{array}$ & $\begin{array}{c}\text { AÇÕES } \\
\text { CON- } \\
\text { JUNTAS }\end{array}$ & $\begin{array}{l}\text { CON- } \\
\text { FIANÇA }\end{array}$ & $\begin{array}{l}\text { REDE X } \\
\text { CON- } \\
\text { FIANÇA }\end{array}$ & $\begin{array}{l}\text { ATIVOS } \\
\text { ESPE- } \\
\text { CÍFICOS }\end{array}$ & $\begin{array}{c}\text { REDE X } \\
\text { ATIVOS } \\
\text { ESPECÍFICOS }\end{array}$ & PORTE & DURAÇÃO \\
\hline Ações conjuntas & 4,5 & 1,34 & 1,0 & & & & & & \\
\hline Confiança & 5,2 & 0,92 & $0,36 * *$ & 1,0 & & & & & \\
\hline Rede $x$ confiança & 15,7 & 6,10 & $0,42 * *$ & 0,19 & 1,0 & & & & \\
\hline Ativos específicos & 3,2 & 1,61 & $0,54 * *$ & 0,13 & $0,43 * *$ & 1,0 & & & \\
\hline Rede $x$ ativos específicos & 10,5 & 7,47 & $0,55^{* *}$ & 0,01 & $0,77 * *$ & $0,78 * *$ & 1,0 & & \\
\hline Porte & 6,1 & 1,40 & $-0,06$ & $-0,31 *$ & 0,09 & $-0,16$ & 0,04 & 1,0 & \\
\hline Duração & 7,7 & 4,73 & $0,26 *$ & 0,08 & 0,11 & 0,08 & 0,09 & $-0,06$ & 1,0 \\
\hline
\end{tabular}


variável, a variável dependente considerada foi "ações conjuntas", e as variáveis independentes foram "confiança" e "investimentos em ativos específicos", inclusive os moderadores e as variáveis de controle. As variáveis foram padronizadas para reduzir a multicolinearidade entre os termos multiplicativos, conforme sugerem Aiken e West (1991). Testes de averiguação de multicolinearidade confirmaram a ausência de problemas. Os valores mais altos de VIF (variation inflation factor) e do índice de condição foram respectivamente 1,40 e 12,24 . Os índices se encontram abaixo do valor limite de 10,00 para o teste VIF e 30,00 para 0 índice de condição, conforme sugerem Hair et al. (1998). Um teste de $F$ incremental foi realizado para comparar o modelo completo com um modelo dos principais efeitos (Aiken e West, 1991). A inclusão dos efeitos moderadores aumentou a variância explicada em quase $8 \%$, se comparado com o modelo básico, indicando que a inclusão das interações foi significativamente garantida ( $F=20,7 ; p<0,001)$. Quando se encontra um efeito moderador significativo, Aiken e West (1991) recomendam avaliar os efeitos altos e baixos desse efeito na relação entre a variável independente e a variável dependente, computando o coeficiente unificado da variável moderadora (1 e - -1).

\section{RESULTADOS}

A Tabela 2 resume os resultados da análise de regressão, apresentando os coeficientes padronizados do modelo. A equação é significativa ao nível de $1 \%$ no teste F. $O R^{2}$ ajustado da equação significativa é de 0,430 e indica que os parâmetros estimados do modelo apresentam um poder explicativo satisfatório. 0 poder explicativo da equação suporta a avaliação individual dos coeficientes.
A hipótese $\mathrm{H} 1$ é significativamente comprovada ( $\beta=$ $0,27 ; p<0,01)$. É provável que os compradores se envolvam em ações conjuntas quando houver confiança no relacionamento com o fornecedor sel ecionado. Isso indica que a confiança permite que as empresas compradoras adquiram conhecimento adequado e experiência, e desenvolvam criatividade para identificar e resolver problemas, bem como para realizar o planejamento de forma efetiva.

A hipótese $\mathrm{H} 2$, que envolve o efeito moderador da rede de relacionamentos na relação entre confiança e ação conjunta, é rejeitada $(\beta=0,11 ; p=0,33)$. Esse resul tado sugere que a confiança é um elemento específico do relacionamento entre fornecedor e comprador, e não é influenciada pela informação obtida junto à rede. Embora não significativo, o coeficiente é positivo, conforme o sinal sugerido na hipótese.

Há evidências para que a hipótese $\mathrm{H} 3$ não seja refutada $(\beta=0,46 ; p<0,01)$. Os resultados mostram a importância das ações conjuntas como uma resposta do comprador para o al to grau de ativos específicos. Essas ações conjuntas podem salvaguardar compradores contra o comportamento oportunista do fornecedor, além de favorecer a coordenação de atividades e recursos envolvidos no relacionamento com os fornecedores.

A rede de informação modera significativamente a relação entre investimento em ativos específicos e ação conjunta $(\beta=0,20, p<0,05)$, comprovando, assim, a hipótese $\mathrm{H} 4$. Analisando o impacto dos ativos específicos na tendência de agir conjuntamente, constatou-se $\beta_{\text {baixo efeito da rede }}=0,26, p<0,01$, enquanto $\beta_{\text {alto efeito da rede }}=0,66, p<0,01$. Obtendo informação das conexões da rede de relacionamento, os compradores aumentam o grau de ativos específicos e de resposta por meio das ações conjuntas, devido ao fato de as informações obtidas na rede poderem evitar um

Tabela 2 - Resultados da análise de regressão.

\begin{tabular}{|c|c|c|c|}
\hline & AÇÕES CONJUNTAS & HIPÓTESES & COMPROVAÇÃO DA HIPÓTESE \\
\hline Confiança & $0,27(2,66) * * *$ & $\mathrm{H} 1$ & Sim \\
\hline Rede $x$ confiança & $0,11(0,97)$ & $\mathrm{H} 2$ & Não \\
\hline Ativos específicos & $0,46(4,30) * * *$ & H3 & $\operatorname{Sim}$ \\
\hline Rede $x$ ativos específicos & $0,20(2,03) * *$ & $\mathrm{H} 4$ & $\operatorname{Sim}$ \\
\hline Porte da empresa & $0,06(0,58)$ & & \\
\hline Duração do relacionamento & $0,19(1,99)^{* *}$ & & \\
\hline$R^{2}$ ajustado & $0,430 * * *$ & & \\
\hline
\end{tabular}


comportamento oportunista e incentivar a integração dos ativos específicos.

0 tamanho do comprador não influencia significativamente 0 grau de ações conjuntas, contrariamente ao que se espera em relação à capacidade de grandes compradores em investir e arriscar. $\mathrm{Na}$ amostra desta pesquisa, o grau de colaboração não é significativamente determinado pelo tamanho da empresa ( $\beta=$ $0,06 ; p=0,56)$, enquanto a duração do relacionamento parece ser contingente ao grau de ações conjuntas $(\beta=0,19 ; p=0,01)$. Essas ações são comuns em relacionamentos mais antigos.

Em uma análise post hoc, avaliou-se se a colaboração por meio das ações conjuntas com fornecedores afeta al guns indicadores financeiros do comprador e a satisfação do comprador no relacionamento com seus fornecedores. Pesquisas anteriores apresentaram evidências de que as ações conjuntas beneficiam os processos operacionais e o desempenho financeiro das empresas (e.g. Mohr e Speckman, 1994; Kim, 1999). Partindo dos indicadores utilizados por essas pesquisas, foram incluídas três questões nos questionários para captar tais indicadores financeiros e de satisfação. Uma pergunta visava verificar até que ponto 0 comprador havia atingido a lucratividade esperada no ano anterior. Perguntou-se sobre a taxa de crescimento em volume de vendas durante os últimos três anos. Incluiu-se também uma questão para captar a satisfação do comprador com as operações e sistemas do fornecedor. Os resultados dos modelos de regressão das ações conjuntas e indicadores financeiros e de satisfação são apresentados na Tabela 3.

De acordo com a tabela 3, foram obtidos efeitos significativos das ações conjuntas nos indicadores financeiro e operacional em todas as equações calculadas. As ações conjuntas influenciam a taxa de crescimento $(\beta=0,22, p<0,05)$, a satisfação $(\beta=0,29, p<0,05)$, e há um efeito marginal na lucratividade $(\beta=0,18, p<$ $0,10)$. Como sugerido por pesquisas anteriores (e.g. Kim, 1999), enfatizam-se também as vantagens da co- laboração no desempenho da empresa. Os resultados sugerem que compradores que mantêm relacionamentos de pouco tempo estão mais propensos a alcançar um alto crescimento das vendas $(\beta=-0,21 ; p=0,01)$. Esse efeito deve ser interpretado considerando a duração média e mínima do relacionamento estudado. Verificando os dados originais, nota-se que a duração do relacionamento é de, no mínimo, dois anos e, em média, maior que sete anos. Portanto, relacionamentos de no mínimo dois anos conferem taxas altas de crescimento. Foi encontrado um efeito negativo do tamanho da empresa na satisfação $(\beta=-0,23, p=0,05)$. N ota-se que compradores menores estão mais propensos a avaliar positivamente as operações e sistemas do fornecedor.

\section{DISCUSSÃO}

Os resultados desta pesquisa devem ser interpretados levando-se em consideração o contexto do setor estudado: de flores e plantas em vasos da Holanda. Esse setor é famoso pela orientação internacional e pelo papel dos leilões, organizado pelas cooperativas de fornecedores. Com a consolidação das redes de supermercados e outras redes de varejo que realizam compras em grande escala, os distribuidores de flores e plantas - os compradores tratados nesta pesquisa perceberam a importância de estabelecer relacionamentos colaborativos com os fornecedores.

Em contraste com as transações impessoais real izadas nos leilões, as transações fora dos leilões exigem relacionamentos colaborativos que permitam aos compradores e distribuidores obter uniformidade de entregas, regularidade de preços e qualidade diferenciada. Explorar o potencial dos fornecedores requer que as operações entre duas empresas sejam integradas nas várias dimensões do relacionamento. Isso envolve ação conjunta extensa e intensa, confiança, fontes de informação que formam a rede organizacional, ativos específicos e duração de relacionamento.

Tabela 3 - Análise de regressão de indicadores financeiros e de satisfação com o relacionamento.

\begin{tabular}{|l|c|c|c|}
\hline & LUCRATIVIDADE & TAXA DE CRESCIM ENTO & SATISFAÇÃO \\
\hline Ações conjuntas & $\mathbf{0 , 1 8}(1,66)^{*}$ & $\mathbf{0 , 2 2}(2,19)^{* *}$ & $\mathbf{0 , 2 9}(2,40)^{* *}$ \\
\hline Porte da empresa & $-0,06(0,47)$ & $0,04(0,34)$ & $\mathbf{- 0 , 2 3}(1,98)^{*}$ \\
\hline Duração do relacionamento & $-0,04(0,34)$ & $-\mathbf{0 , 2 1}(2,19)^{* *}$ & $0,03(0,23)$ \\
\hline$R^{2}$ ajustado & 0,03 & 0,05 & 0,11 \\
\hline
\end{tabular}

$* * p<0,05, * p<0,10$

Notas: Os coeficientes de regressão são os coeficientes padronizados $(\beta)$ e o teste de t entre parênteses. 
A realização de ações conjuntas requer atenção cuidadosa dos tomadores de decisão, devido às diferentes posturas dos compradores no relacionamento com os fornecedores. A resposta das ações conjuntas do comprador parece ser moldada pela confiança no fornecedor. Quando a confiança é alta, os relacionamentos tendem a ser mais colaborativos. Além disso, um grau relativamente al to de ações conjuntas é empreendido com o intuito de proteger os investimentos em equipamentos e pessoal disponibilizados exclusivamente para um fornecedor. Por meio das ações conjuntas, os compradores conseguem uma melhor integração dos recursos e atividades envol vidas com o fornecedor. As ações conjuntas podem minimizar os custos sistêmicos da transação relacionados aos altos investimentos em ativos específicos.

A rede organizacional estimula os relacionamentos colaborativos com fornecedores, proporcionando um contexto em que as empresas tendem a investir mais em ativos específicos e a colaborar mais com os fornecedores. A informação obtida na rede pode reduzir a atitude oportunista de fornecedores e proteger os investimentos realizados no relacionamento, além de incentivar os relacionamentos colaborativos com fornecedores. Esta pesquisa comprovou os efeitos benéficos da rede organizacional de relacionamentos, ao apresentar evidências de diferentes efeitos moderadores da rede nas ações conjuntas.

\section{CONSIDERAÇÕES FINAIS}

\section{Implicações para a prática gerencial}

Os estudos sobre a gestão de relacionamentos têm constituído foco de pesquisas no setor automobilístico (Dyer, 1996), de vestuário (Uzzi, 1997) e de microel etrônica (Saxenian, 1991). N os agronegócios, os estudos vêm avançando na área de supermercados (Hobbs, 1996), máquinas agrícolas (Provan e Skinner, 1989) e distribuição (Claro et al., 2002). Todos esses estudos, inclusive o relatado neste artigo, se concentram no desenvolvimento de relacionamentos colaborativos com fornecedores de produtos críticos para 0 comprador. Esses fornecedores podem eventual mente atuar como líderes e estimular outros fornecedores a manter um mesmo tipo de relacionamento com o distribuidor. Os resultados desta pesquisa podem auxiliar gestores brasileiros não apenas do setor de flores, mas também em outros setores que necessitem estabelecer relacionamentos colaborativos.
0 relacionamento colaborativo entre fornecedor e comprador representa um ativo importante da empresa e deve ser tratado com lógica similar àquela aplicada a qualquer outro tipo de investimento. As ações conjuntas devem ser entendidas por administradores como ações que integram e protegem investimentos em ativos específicos. Elas são capazes de apoiar administradores na mitigação de tendências oportunistas que podem reduzir o valor dos investimentos específicos.

Esta pesquisa procurou mostrar a importância da confiança como motivadora da colaboração. Cinco iniciativas podem ser sugeridas com o intuito de desenvolver e manter a confiança em um relacionamento. Primeiro, os gestores podem calcular os custos e as recompensas envolvidos caso um fornecedor esteja trapaceando ou cooperando (Williamson, 1985). O comprador pode deduzir que é conveniente confiar em seu fornecedor na medida em que os benefícios da trapaça não excedam os custos de o fornecedor ser pego trapaceando. Segundo, os gestores podem prever 0 comportamento do fornecedor. A confiança é derivada das expectativas do comportamento do fornecedor, o que é baseado na reputação e nas reivindicações presentes, tanto implícitas quanto explícitas (Doney et al., 1998). Terceiro, a confiança também é influenciada pelas intenções do fornecedor. Os gestores podem interpretar o discurso e o comportamento do fornecedor e, assim, tentar determinar suas intenções no relacionamento (Ganesan, 1994). Quarto, a confiança pode ser construída com base em uma avaliação da capacidade do fornecedor de cumprir suas obrigações e atender às expectativas do comprador. Finalmente, a confiança pode ser transferida na rede organizacional; ou seja, pode ser transmitida de uma fonte confiável de informação para outro indivíduo ou grupo com qual o comprador mantenha relacionamento. Esse processo de transferência permite uma propagação da confiança de uma empresa conhecida para outra, desconhecida.

É importante que os gestores percebam a importância da rede organizacional de relacionamentos. As empresas, por sua vez, podem incentivar as iniciativas dos gestores para o desenvolvimento de relacionamentos com outras empresas. Isso faz com que esses gestores formem suas próprias redes de relacionamentos, capazes de fornecer informações valiosas e apoiar as decisões envolvidas no relacionamento com fornecedores.

Os resultados dessa pesqui sa sugerem que a rede de um comprador pode aumentar a relação entre investimentos em ativos específicos e ações conjuntas. 0 sim- 
ples processo de coletar informação de fontes conhecidas e desenvolver novas fontes de informação pode aumentar substancialmente as chances de sucesso do comprador.

Os resultad os sugerem que coordenar relacionamentos colaborativos com fornecedores significa muito mais do que realizar uma boa compra. Os fornecedores podem real izar muito mais do que apenas entregar os produtos no prazo correto e com preços razoáveis. Podem realimentar continuamente a confiança neles depositada, investir em ativos para o relacionamento e, acima de tudo, responder às ações conjuntas dos compradores.

Na prática empresarial, relacionamentos colaborativos constituem uma idéia consolidada. 0 postulado básico desta pesquisa é que uma empresa é capaz de coordenar relacionamentos colaborativos com fornecedores por meio das ações conjuntas. No contexto em que o model o foi testado, distribuidores de flores e plantas em vasos têm procurado canais de comercial ização que sejam capazes de reduzir as imprevisibilidades quanto ao preço e ao volume dos produtos e, adicional mente, reduzir as restrições rel acionadas às entregas. Desse modo, foi possível criar vantagens competitivas e, a partir dessas condições, realizar investimentos em ativos específicos e estabelecer relacionamentos mais próximos com os fornecedores.

No entanto, na ausência de vantagens competitivas, as ações conjuntas não propiciam efeitos benéficos; ao contrário, podem levar a conseqüências negativas devido aos custos associados à utilização de um canal de comercialização diferente do tradicional, como o leilão.

\section{Limitações do estudo e sugestões para futuras pesquisas}

Este trabalho utilizou um desenho transversal de pesquisa, o que limita a realização de inferências. Sugerese que se realizem pesquisas com desenho longitudinal, uma vez que permitem comprovar a causalidade das relações. Outra forma de lidar com essa limitação é o uso de modelos estatísticos baseados em inteligência artificial, que permitem determinar a orientação do efeito causal (Besseler e $\mathrm{N}$ athan, 2001).

A general ização dos resultados deve ser considerada com restrições. A amostra utilizada pode limitar a variação de algumas das dimensões e refletir particularidades do setor estudado; por exemplo, as cooperativas dos fornecedores oferecem ampla infra-estrutura para encontros entre os compradores e os fornecedores. Adicional mente, há a questão da distribuição geo- gráfica dessas empresas, cuja distância máxima é de 200 quilômetros. A pequena distância certamente estimula visitas e contatos pessoais. Considerando essas particularidades, encoraja-se a realização de estudos adicionais, a fim de reproduzir e expandir os resultados desta pesquisa para outros setores.

Os resultados apresentados real çam a inclusão do relacionamento com fornecedores na agenda para futuras pesquisas, ampliando o tema da gestão de relacionamentos além da transação e dos relacionamentos baseados em preços (Anderson et al., 1994). Além disso, procurou-se mostrar que as ações conjuntas são significativamente influenciadas pela confiança depositada no fornecedor, pelos ativos específicos e pelo efeito moderador da rede de informação. I gnorar quaisquer desses elementos da gestão de relacionamentos pode conduzir a uma análise insuficiente e incompleta dos relacionamentos com os fornecedores. Por isso, futuras pesquisas na área de coordenação de relacionamentos devem considerar as vantagens de se combinarem as diferentes correntes teóricas.

\section{REFERÊNCIAS BIBLIOGRÁFICAS}

AIKEN , L.; WEST, S. M ultiple regression: testing and interpreting interactions. Newbury Park, CA: Sage Publications, 1991.

ANDERSON, E.; WEITZ, B. Determinants of continuity in conventional industrial channel dyads. Market Science, v. 8, n. 4, p. 310-323, 1989.

ANDERSON, J. C.; NARUS, J. A. A model of distributor firm and manufacturer firm working partnerships. Journal of Marketing , v. 54, n. 1, p. $42-58,1990$.

ANDERSON, J. C.; HAKANSSON, H.; JOHANSON, J. Dyadic business relationship within a business network context. Journal of Marketing, $v$. 58, n. 4, p. 22-38, 1994.

ARMSTRONG, J. S.; OVERTON, T. S. Estimating nonresponse bias in mail survey. Journal of Marketing Research, v. 14, n. 3, p. 396-402, 1977.

BENSAOU, M.; VENKATRAMAN, N. Configurations of interorganizational relationships: a comparison between U.S. and Japanese automakers. M anagement Science, v. 41, n. 9, p.1471-1492, 1995.

BESSLER D. A.; NATHAN L. Economic development: evidence from directed acyclic graphs. The M anchester School, v. 69, p. 457-76, 2001.

BLANKENBURG, D.; ERIKSSON, K.; JOHANSON, J. Creating value through mutual commitment to business network relationships. Strategic Management Journal, v. 20, n. 5, p. 467-486, 1999. 
CLARO, D. P. M anaging Business N etwork and Buyer-Supplier Relationship. Veenendal: Universal Press, 2004.

CLARO, D. P.; CLARO, P. B. de O.; HAGELAAR, G. Rede estratégica na seleção e manutenção de relacionamentos com fornecedores: 0 caso MONL. Revista de Administração da USP, v. 37, n. 3, p. 6-18, 2002.

DONEY, P. M.; CANNON, J. P.; MULLEN, M. R. Understanding the influence of national culture on the development of trust. Academy of M anagement Review, v. 23, n. 3, p. 601-620, 1998.

DWYER, F. R.; SCHURR, P. H.; OH, S. Developing buyer-seller relationships. Journal of Marketing, v. 5, n. 2, p. 11-27, 1987.

DYER, J. H. Specialized supplier networks as a source of competitive advantage: evidence from the auto industry. Strategic M anagement Journal, v. 17, n. 4, p. 271-291, 1996.

DYER, J. H.; SINGH, H. The relational view: cooperative strategy and sources of interorganizational competitive advantage. Academy of M anagement Review, v. 23, n. 4, p. 660-679, 1998.

FORD, D. et al. Managing Business Relationships. Chichester: Wiley, 2003.

GALFORD, R.; DRAPEAU, A. S. The enemies of trust. Harvard Business Review, p. 88-95, February 2002.

GANESAN, S. Determinants of long-term orientation in buyer-seller relationships. Journal of Marketing, v. 58, n. 2, p. 1-19, 1994.

GRANOVETTER, M. Economic action and social structure: the problem of embeddedness. American Journal of Sociology, v. 91, n. 3, p. 481-510, 1985.

GULATI, R.; NOHRIA, N.; ZAHEER, A. Strategic Networks. Strategic Management Journal, v. 21, n. 3, p. 203-215, 2000.

HAIR, J. F.; ANDERSON, R.; TATHAM, R. L.; BLACK, W. C. Multivariate data Analysis. Upper Saddle River: Prentice Hall, 1998.

HEIDE, J. B. Interorganizational governance in marketing channels. Journal of Marketing, v. 58, n. 1, p. 71-85, 1994.

HEIDE, J. B.; JOHN , G. Alliances in industrial purchasing: the determinants of joint action in buyer supplier relationships. Journal of M arketing Research, v. 27, n. 1, p. 24-36, 1990.

HEIDE, J. B.; JOHN, G. Do norms matter in marketing relationships? Journal of Marketing, v. 56, n. 2, p. 32-44, 1992.

HOBBS, J. E. A transaction cost analysis of quality, traceability and animal welfare issues in UK beef retailing. British Food Journal, v. 98, n. 6, p. 1626, 1996.

JORESKOG, K. G.; SORBOM, D. LISREL 8: structural equation modeling with the SIMPLIS command language. Hillsdale, NJ: Lawrence Erlbaum Associates, 1996.
KIM , K. On determinants of joint action in industrial distributor-supplier relationships: beyond economic efficiency. International Journal of Research in Marketing, v. 16, n. 3, p. 217-236, 1999.

LUSCH, R. F.; BROW N, J. R. Interdependency, contracting, and relational behavior in market channels. Journal of Marketing, v. 60, n. 4, p. 19-38, 1996.

MACNEIL, I. R. Economic analysis of contractual relations: its shortfalls and the need for a 'rich classificatory apparatus'. N orthwestern U niversity Law Review, v. 75, n. 1, p. 1018-1063, 1981.

MOHR, J. J.; SPECKMAN, R. Characteristics of partnership success: partnership attributes, communication behavior, and conflict resolution techniques. Strategic Management Journal, v. 15, n. 2, p. 135-152, 1994.

MOORMAN, C.; ZALTMAN, G.; DESH PANDE, R. Relationships between providers and users of market research: the dynamics of trust within and between organizations. Journal of Marketing Research, v. 29, n. 3, p. 314328, 1992.

MORGAN, R. M.; HUNT, S. D. The commitment-trust theory of relationship marketing. Journal of M arketing, v. 58, n. 3, p. 20-38, 1994.

NEVES, M. F. Um modelo para construir ou revisar contratos em redes de empresas (networks). Revista de Economia e Administração, v. 1, n. 2, 2002.

OMTA, S. W. F.; TRIENEKENS, J. H.; BEERS, G. The knowledge domain of chain and network science. Journal of Chain and N etwork Science, v. $1, n$. 2, p. 1-11, 2001

PROVAN, K. G.; SKINNER, S. J. Interorganizational dependence and control as predictors of opportunism in dealer-supplier relations. Academy of Management Journal, v. 32, n. 1, p. 202-212, 1989.

SAXENIAN, A. The origin and dynamics of production networks in Silicon Valley. Research Policy, v. 10, p. 423-437, 1991.

STERN, L. W.; EL-ANSARY, A. I.; COUGHLAN, A. T. Marketing Channels. Upper Saddle River, NJ: Prentice Hall. 1996.

THORELLI, H. B. Networks: between markets and hierarchies. Strategic Management Journal, v. 7, n. 1, p. 37-51, 1986.

UZZI, B. Social structure and competition in interfirm networks: the paradox of embeddedness. Administrative Science Quarterly, v. 42, n. 1, p. 35-67, 1997.

WICKS, A. C.; BERMAN, S. L.; JONES, T. M. The structure of optimal trust: moral and strategic implications. Academy of Management Review, $\mathrm{v}$. 24, n. 1, p. 99-116, 1999.

WILLIAMSON, O. E. The economic institutions of capitalism. N ew York: Free Press. 1985. 
YILMAZ, C.; HUNT, S.D. Salesperson cooperation: the influence of relational, task, organizational, and personal factors. Journal of the Academy of Marketing Science, v. 29, n. 4, p. 335-357, 2001.

ZAHEER, A.; MCEVILY, B.; PERRONE, V. Does trust matter? Exploring the effects of interorganizational and interpersonal trust on performance. Organization Science, v. 9, n. 2, p. 141-159, 1998.

ZAND, D. E. Trust and managerial problem solving. Administrative Science Quarterly, v. 17, n. 2, p. 229-239, 1972.

ZYLBERSZTAJN, D.; JANK, M. S.; KOOL, M.; SLUYS, T. Holanda: um modelo de agribusiness. São Paulo: USP, 1992. 95 p.
ZYLBERSZTAJN, D. Estruturas de governança e coordenação do agribusiness: uma aplicação da nova economia das instituições. São Paulo: USP, 1995. 238 p. (Tese de Livre Docência em Administração.)

\section{NOTA}

Os autores agradecem à CAPES (Projeto BEX 1257/98-6), principal órgão financiador do projeto do qual esta pesquisa faz parte, aos avaliadores pelos valiosos comentários e sugestões que auxiliaram na elaboração da versão final deste artigo, bem como aos gerentes que forneceram as informações para testar o modelo conceitual.

\section{Artigo recebido em 25.08.2003. Aprovado em 07.06.2004.}

\section{Danny Pimentel Claro}

Professor das Faculdades I bmec - SP. Doutor em Administração pela U niversidade de Wageningen, Holanda. Pós-doutorando da Faculdade de Economia, Administração e Contabilidade da Universidade de São Paulo. Pesquisador do Grupo Pensa da USP. Interesses de pesquisa nas áreas de administração de relacionamentos de negócio, canal de marketing, networks e administração de cadeia de produção.

E-mail: danny@pensa.org.br

Endereço: Rua Valson Lopes, 101, Butantã, São Paulo-SP, 05508-900.

\section{Priscila Borin de Oliveira Claro}

Doutoranda em Administração na U niversidade Federal de Lavras. Interesses de pesquisa nas áreas de gestão ambiental, cadeias de produção e desenvolvimento.

E-mail: priclaro@yahoo.com.br

Endereço: Rua Coronel Alvim de M enezes, 3, Jardim Floresta, Lavras-MG, 37200-000. 